University of Nebraska - Lincoln

DigitalCommons@University of Nebraska - Lincoln

Faculty Publications from the Department of Electrical \& Computer Engineering, Department Electrical and Computer Engineering

7-1-1992

\title{
Graded refractive index silicon oxynitride thin film characterized by spectroscopic ellipsometry
}

\author{
Paul G. Snyder \\ University of Nebraska-Lincoln, psnyder1@unl.edu \\ Yi-Ming Xiong \\ University of Nebraska-Lincoln \\ John A. Woollam \\ University of Nebraska-Lincoln, jwoollam1@unl.edu
}

Follow this and additional works at: https://digitalcommons.unl.edu/electricalengineeringfacpub

Part of the Electrical and Computer Engineering Commons

Snyder, Paul G.; Xiong, Yi-Ming; and Woollam, John A., "Graded refractive index silicon oxynitride thin film characterized by spectroscopic ellipsometry" (1992). Faculty Publications from the Department of Electrical and Computer Engineering. 69.

https://digitalcommons.unl.edu/electricalengineeringfacpub/69

This Article is brought to you for free and open access by the Electrical \& Computer Engineering, Department of at DigitalCommons@University of Nebraska - Lincoln. It has been accepted for inclusion in Faculty Publications from the Department of Electrical and Computer Engineering by an authorized administrator of DigitalCommons@University of Nebraska - Lincoln. 


\title{
Graded refractive index silicon oxynitride thin film characterized by spectroscopic ellipsometry
}

\author{
Paul G. Snyder, Yi-Ming Xiong, and John A. Woollam \\ Center for Microelectric and Optical Materials Research, Department of Electrical Engineering, \\ University of Nebraska, Lincoin, Nebraska 68588-0511
}

Ghanim A. Al-Jumaily

M/S 179-111, Jet Propulsion Laboratory, Pasadena, California 91109

F. J. Gagliardi

Barr Associates, Inc, Westford, Massachusetts 01886

(Received 13 November 1991; accepted 30 March 1992)

\begin{abstract}
A graded refractive index silicon oxynitride $\left(\mathrm{SiO}_{x} \mathrm{~N}_{y}\right)$ thin film was prepared on a silicon substrate by ion assisted deposition. Spectroscopic ellipsometry (SE) was used to optically analyze the film. The measured SE spectra $(2500-8200 \AA)$ were analyzed with several fitting models, whose construction was based on an Auger depth profile of the film. In each model, the optical response of $\mathrm{SiO}_{x} \mathrm{~N}_{y}$ was described using the Bruggeman effective medium approximation, by modeling it as a physical mixture of two distinct phases: silicon dioxide and silicon nitride. Grading was modeled by varying the silicon nitride volume fraction with depth below the surface, according to an assumed profile. Fitting results were very sensitive to the profile chosen, which was different for each model. Experimentation with the profile led to a model which produced a remarkably good fit, over the entire spectral range. As a result, the film thickness and its refractive index profile were determined. The index profile determined by SE analysis was found to be consistent with the Auger profile.
\end{abstract}

\section{INTRODUCTION}

Graded refractive index optical thin films, such as rugate filters, are being increasingly recognized and considered as an attractive alternative to traditional multilayer dielectric stack devices for spectral filters and broad band antireflection coatings. ${ }^{1,2}$ Several methods are used to fabricate the films, ${ }^{3}$ including ion assisted deposition (IAD) ${ }^{4,5}$ In this method, the film compositional variation is realized by reactive ion beams through control of the relative gas fluxes. The dependencies of refractive index in the composition can, in turn, be employed for fabrication of desired optical films.

An effective and nondestructive means of accurately determining the film thickness and its refractive index profile is needed to facilitate film analysis. In this work, spectroscopic ellipsometry (SE), ${ }^{6}$ a nondestructive optical technique, was used to study an IAD deposited graded refractive index silicon oxynitride $\left(\mathrm{SiO}_{x} \mathrm{~N}_{y}\right)$ thin film. The ellipsometrically measured spectra were analyzed with several fitting models, constructed based on an Auger depth profile of the film. The model calculations were carried out by assuming $\mathrm{SiO}_{x} \mathrm{~N}_{y}$ to be a physical mixture ${ }^{7-9}$ of two distinct phases, silicon dioxide $\left(\mathrm{SiO}_{2}\right)$ and silicon nitride $\left(\mathrm{Si}_{3} \mathrm{~N}_{4}\right)$, using the Bruggeman effective medium approximation (EMA).$^{10}$ As a result, the film thickness and its refractive index profile were determined.

\section{EXPERIMENTAL}

\section{A. Sample preparation}

The $\mathrm{SiO}_{x} \mathrm{~N}_{y}$ film was deposited onto a $50 \mathrm{~mm}$ diam $\mathrm{Si}(100)$ substrate wafer in a Balzers 760 system. The sub- strate was heated to about $300^{\circ} \mathrm{C}$ with a quartz halogen heater. The deposition system was cryogenically pumped to a base pressure of $1.50 \times 10^{-6}$ Torr. High purity $(99.999 \%)$ Si was evaporated using one of two electron evaporation sources, where the evaporation rate was controlled by a crystal rate controller. An $8 \mathrm{~cm}$ Kaufman ion source with beam expanding grids was used for precleaning and ion bombardment during deposition, and was located $35 \mathrm{~cm}$ away from the substrate. The bombarding species were nitrogen ions, with beam energy and current set at $500 \mathrm{eV}$ and $100 \mathrm{~mA}$, respectively. The relative arrival ratio of ions to $\mathrm{Si}$ atoms was about 1:1. The film chemistry (composition versus thickness) was controlled by linearly varying the ratio of nitrogen flowing into the-ion source and oxygen in the backfill. The film compositional variation was measured by sputter depth profiling by Auger electron spectroscopy (AES).

\section{B. Ellipsometry}

SE was used to optically characterize the deposited $\mathrm{SiO}_{x} \mathrm{~N}_{y}$ film. Details about ellipsometry can be found in Ref. 11 , and only a brief description is given here. In ellipsometry, linearly polarized light is incident at an oblique angle onto the sample. The refiected light from the sample surface is, in general, elliptically polarized. The new polarization state of the reflected light, containing information about sample's properties, is determined using a polarizer prism. The ellipsometrically measured data are $\tan \psi$ and $\cos \Delta$, defined by $\tan \psi \cdot \exp ^{i \Delta}=R_{p} / R_{s}$, where $R_{p}$ and $R_{s}$ are the complex reflection coefficients for light polarized parallel $(p)$ and perpendicular $(s)$ to the plane of incidence, respectively. For a substrate covered with a thin 


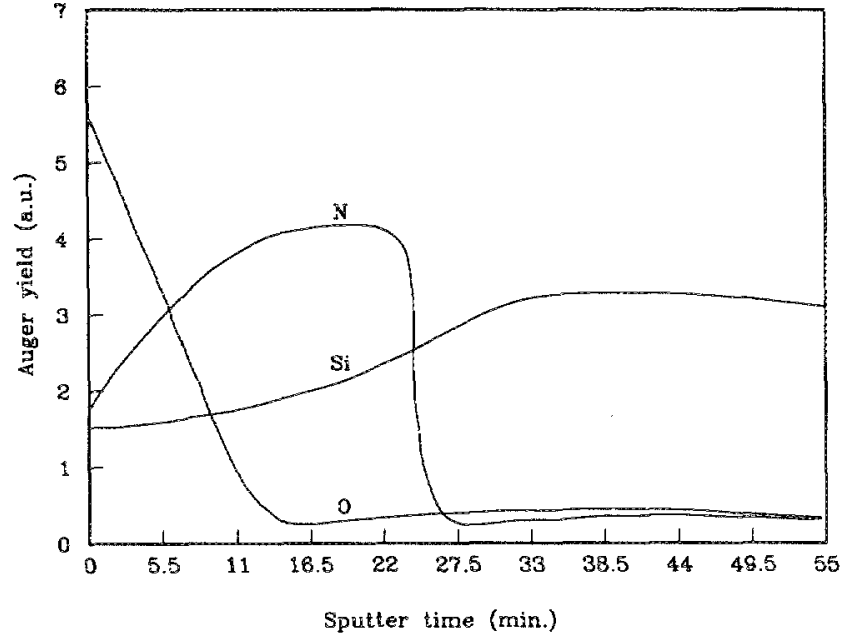

Fig. 1. Auger in-depth profile of the graded refractive index $\mathrm{SiO}_{x} \mathrm{~N}_{y}$ deposited on Si substrate.

film, the measured data are numerically fitted with an appropriate model, which should best represent the sample under study. In this model, the unknown parameters, such as film thickness, optical constants, and even constituent volume fractions (if the film is a composite materiai) can be chosen as fitting parameters to be determined from standard ellipsometric equations. ${ }^{11}$ Using a regression algorithm, ${ }^{12}$ the fitting parameters are varied, until the squared differences between the measured and calculated data at the corresponding wavelengths and angles of incidence are minimized. The quality of the fit can be judged quantitatively by the biased estimator $(\sigma)$, defined by

$$
\sigma=\frac{1}{N} \sum_{i=1}^{N}\left(\frac{\left(\psi_{i}^{m}-\psi_{i}^{c}\right)^{2}}{\delta \psi_{i}^{2}}+\frac{\left(\Delta_{i}^{m}-\Delta_{i}^{c}\right)^{2}}{\delta \Delta_{i}^{2}}\right),
$$

where $N$ is the total number of measurements, and superscripts $m$ and $c$ stand for the measured and calculated data, respectively. The experimental errors in $\psi_{i}$ and $\Delta_{i}$ are given by $\delta \psi_{i}$ and $\delta \Delta_{i}$, which are estimated values.

All SE measurements were performed at room atmosphere with an automatic rotating analyzer ellipsometer (similar to that described in Ref. 13, with the added capability of variable angle of incidence), at $75^{\circ}$ angle of incidence and in the $2500-8200 \AA$ spectral range at $50 \AA$ intervals. The value of angle chosen here is not critical, because of the large variations in the spectra due to optical interference in the transparent film. Prior to and during the measurements, no chemical treatment was made on the sample surface. The average uncertainties in the $\psi$ and $\Delta$ measurements were within $\pm 0.01^{\circ}$ and $\pm 0.03^{\circ}$, respectively. The angle of incidence was accurate to within $\pm 0.01^{\circ}$. The beam diameter was about $1 \mathrm{~mm}$.

\section{MODELNG}

The optical properties of $\mathrm{SiO}_{x} \mathrm{~N}_{y}$ have been studied before (see Refs. 7-9 and 14-15). As indicated in Refs. 7 and 9 , the optical behavior of homogeneous $\operatorname{SiO}_{x} \mathrm{~N}_{y}$ can be successfully described by modeling it to be a simple dielectric
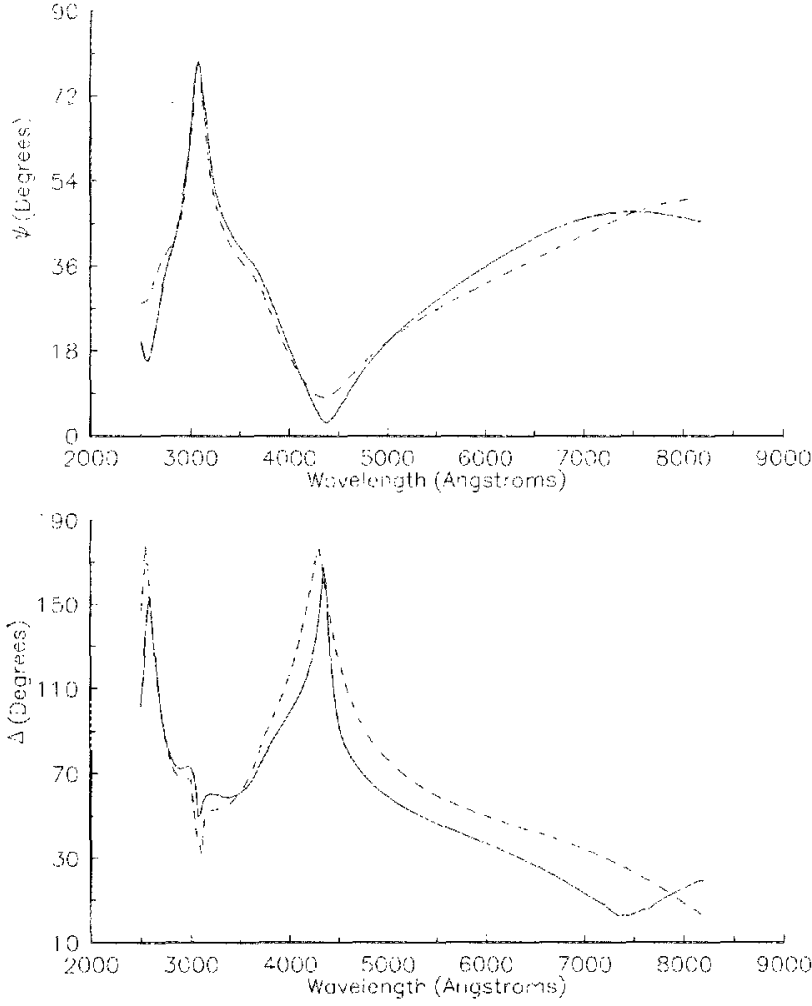

FIG. 2. Measured (solid lines) and calculated (dashed lines) $\psi$ and $\Delta$ spectra at $75^{\circ}$ angle of incidence, obtained using the first fitting model described in the text.

physical mixture of two distinct phases, $\mathrm{SiO}_{2}$ and $\mathrm{Si}_{3} \mathrm{~N}_{4}$, using the Bruggeman EMA. According to the EMA, the effective refractive index $n$ of $\mathrm{SiO}_{x} \mathrm{~N}_{y}$ can be obtained from the following equations:

$$
f_{\mathrm{SiO}_{2}} \frac{n_{\mathrm{SiO}_{2}^{2}-n^{2}}}{n_{\mathrm{SiO}_{2}^{2}}+2 n^{2}}+f_{\mathrm{Si}_{3} \mathrm{~N}_{4}} \frac{n_{\mathrm{Si}_{3} \mathrm{~N}_{4}^{2}}-n^{2}}{n_{\mathrm{Si}_{3} \mathrm{~N}_{4}^{2}}+2 n^{2}}=0
$$

and

$$
f_{\mathrm{SiO}_{2}}+f_{\mathrm{Si}_{3} \mathrm{~N}_{4}}=1,
$$

where $f_{\mathrm{SiO}_{2}}$ and $f_{\mathrm{Si}_{3} \mathrm{~N}_{4}}$ represent the relative volume fractions of $\mathrm{SiO}_{2}$ and $\mathrm{Si}_{3} \mathrm{~N}_{4}$ in the mixture, and $n_{\mathrm{SiO}_{2}}$ and $n_{\mathrm{Si}_{3} \mathrm{~N}_{4}}$ are the refractive indices of $\mathrm{SiO}_{2}$ and $\mathrm{Si}_{3} \mathrm{~N}_{4}$, respectively. Furthermore, at each wavelength (within the given spectral range), the refractive index of $\mathrm{SiO}_{x} \mathrm{~N}_{y}$ has been found to be a linear function of its constituent volume fraction (i.e., $f_{\mathrm{SiO}_{2}}$ or $\left.f_{\mathrm{Si}_{3} \mathrm{~N}_{4}}\right)^{7,9}$

The $\mathrm{SiO}_{x} \mathrm{~N}_{y}$ film studied in this work is inhomogeneous, i.e., its refractive index profile varies with depth. AES depth profile of the sample in Fig. 1 clearly shows the inhomogeneity of film composition versus its depth (corresponding roughly with the sputter time scale). Thus, it would be unphysical to model this film as a homogeneous EMA mixture. From Fig. 1, it can be seen that the N/O ratio is large and fairly constant, starting from the $\mathrm{SiO}_{x} \mathrm{~N}_{y}$ fim/Si substrate interface to the point corresponding to about $15 \mathrm{~min}$ into the sputtering, and that the ratio de- 

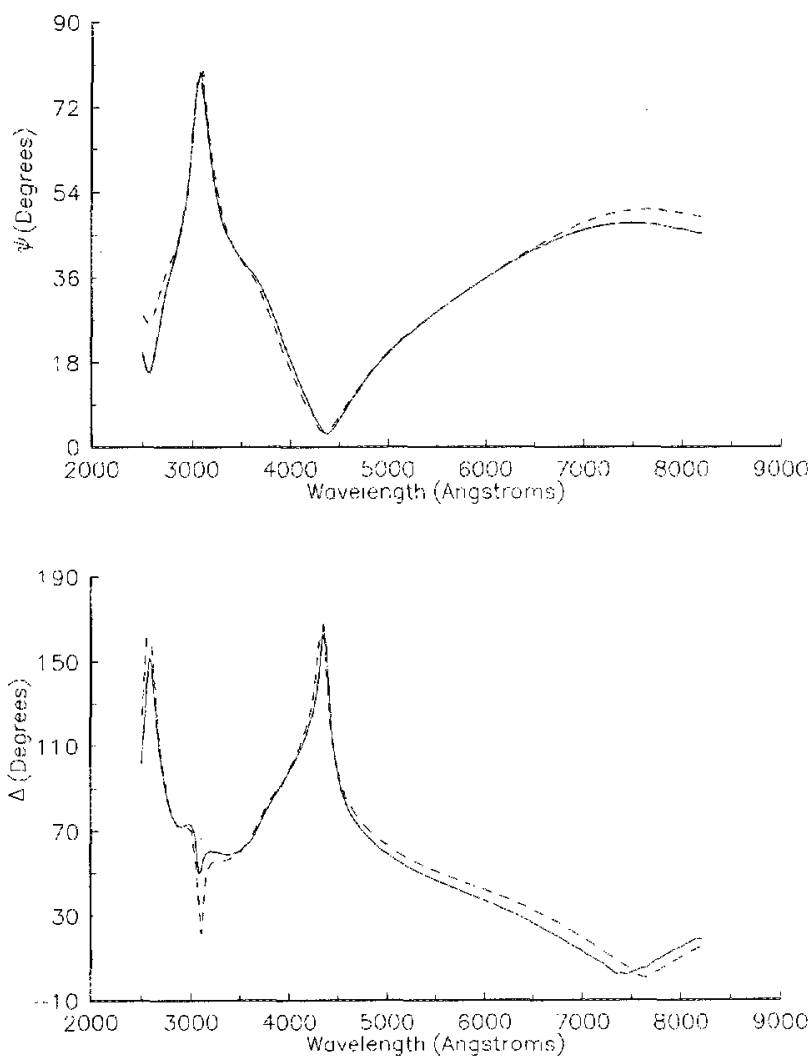

FIG. 3. Measured (solid lines) and calculated (dashed lines) $\psi$ and $\Delta$ spectra at $75^{\circ}$ angle of incidence, obtained using the second fitting model described in the text.

creases continuously, in a nearly linear fashion, from that point $(15 \mathrm{~min})$ on to the sample surface $(0 \mathrm{~min})$.

Based on these observations, three different fitting models were constructed for SE data analysis. The main differences are in the assumed profile shapes. The simplest model, assuming a uniform layer of $\mathrm{SiO}_{x} \mathrm{~N}_{y}$ with constant composition, was used for comparison with the graded index models, to illustrate the gross effects of a graded versus an ungraded layer. The second model assumed a simple linear variation in the relative volume fraction of $\mathrm{Si}_{3} \mathrm{~N}_{4}$, starting from $100 \%$ at the film/substrate interface, and decreasing towards the surface (where the film was oxygen rich). The third model, a refinement of the second, added another linearly graded interfacial layer near the substrate, which was less steeply graded than the layer above it.

To approximate the effects of grading, each graded layer was divided into many sublayers of equal thickness. Each sublayer had a uniform composition, and the composition from one sublayer to the next was varied in a linear staircase fashion (see Figs. 4 and 6 ). In practice, division into ten sublayers produced a very good approximation to continuous grading.

In carrying out the above multilayer model calculations, the layer's total thickness, and its starting and ending layer volume fractions were chosen as the fitting parameters. The refractive indices of $\mathrm{SiO}_{2}, \mathrm{Si}_{3} \mathrm{~N}_{4}$, and $\mathrm{Si}$ substrate, were taken as the bulk values given in the literature. ${ }^{16}$ It is known that very thin films often have different optical con-
TABLE I. SE determined results, obtained using the three different fitting models described in the text.

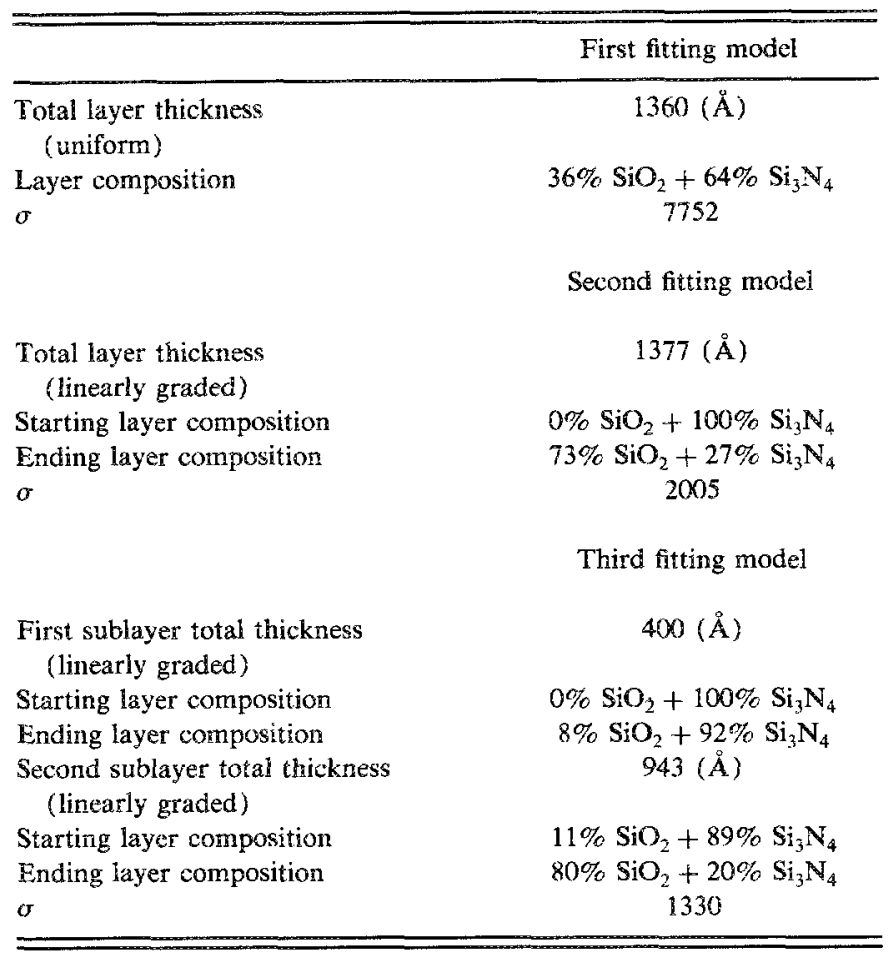

stants from the bulk. However, the validity of using bulk values in this study was verified, by accurately modeling measurements on pure $\mathrm{SiO}_{2}$ and $\mathrm{Si}_{3} \mathrm{~N}_{4}$ films of roughly the same thickness.

\section{RESULTS AND DISCUSSION}

The film thickness and its refractive index profile were determined by numerically fitting the SE data, using the above-described fitting models. Figs. 2 and 3 show the measured and calculated (best-fit) $\psi$ and $\Delta$ spectra obtained using the first and second models, respectively. The $\sigma$ values in Table I also provide a quantitative comparison

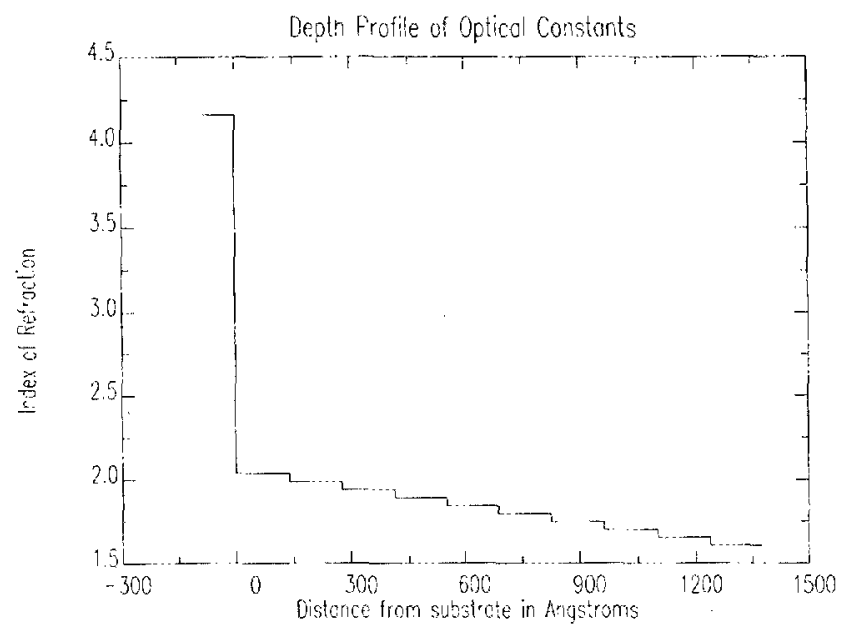

FIG. 4. SE determined refractive index profile of the film at $5350 \AA$ wavelength, obtained using the second fitting model described in the text. 

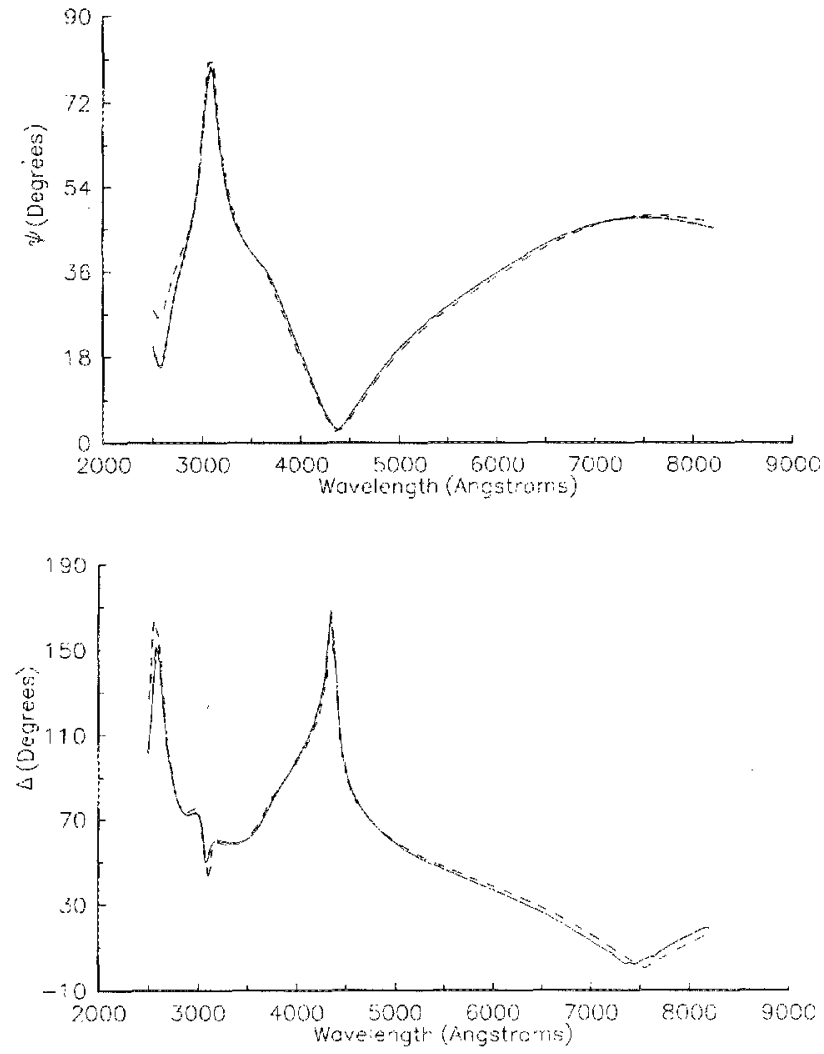

FrG. 5. Measured (solid lines) and calculated (dashed lines) $\psi$ and $\Delta$ spectra at $75^{\circ}$ angle of incidence, obtained using the third fitting model described in the text.

of the results. These figures graphically illustrate how much the fits are improved in going from a uniform to a graded profile. Peaks and valleys in the $\psi$ and $\Delta$ spectra are due to the optical interference within the film. Their positions, shapes, and amplitudes are very sensitive to the layer thickness and assumed profile. Clearly, the first fitting model only yields a qualitative fit. With the second model, the fit is much improved, indicating that the assumed profile is row much closer to the real profile. The associated refractive index profile (based on the best-fit results) is shown in Fig. 4. The best results were obtained from the third fitting model. Fitting results for this model, shown in Fig. 5, are visibly better than for the other two models. Figure 6 illustrates the associated refractive index profile. This index profile is also very consistent with the Auger profile (Fig. 1). It clearly demonstrates that the refractive index profile of the $\mathrm{SiO}_{x} \mathrm{~N}_{y}$ film is indeed graded nonuniformly, as suggested by the Auger profile. The final fitting results (i.e., thicknesses, volume fractions, and the $\sigma$ values) are given in Table $\mathbb{I}$.

The large values of $\sigma$ in Table I indicate (a) the estimates for $\delta \psi$ and $\delta \Delta$ were too low (which is likely), and/ or (b) the model used did not perfectly reflect the true structure and refractive index profile in the sample. Considering that a complex profile was modeled simply, with only a few fitting parameters, and that strong optical interference structure was present in the data, the $\sigma$ values obtained are not unreasonable.

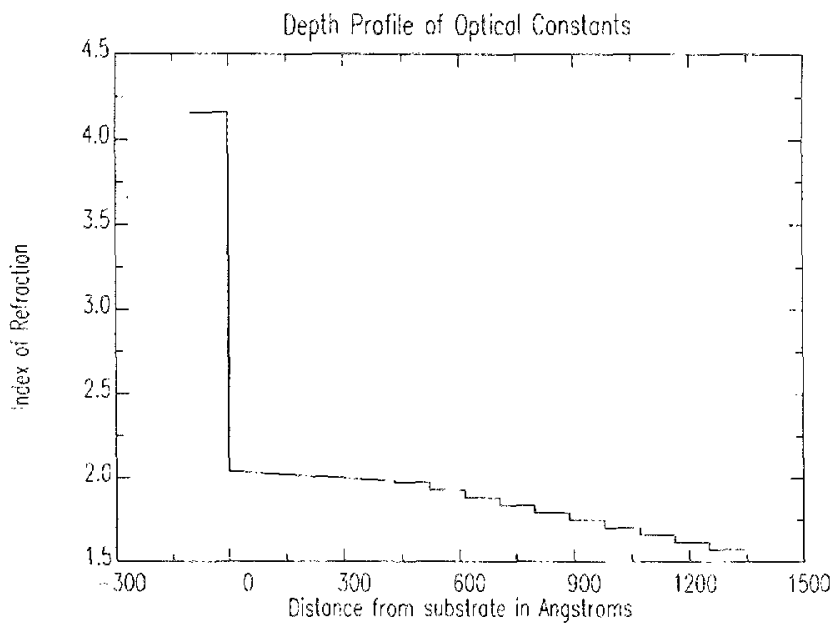

FIG. 6. SE determined refractive index profile of the film at $5350 \AA$ wavelength, obtained using the third fitting model described in the text.

Another model was constructed to determine whether an interfacial layer existed at the $\mathrm{SiO}_{x} \mathrm{~N}_{y}$ film/Si substrate boundary. The model was similar to the third model described above, but added a thin interfacial layer, which consisted of a mixture of equal volume fractions of Si and $\mathrm{Si}_{3} \mathrm{~N}_{4}$. The mixture's optical constants were modeled with the Bruggeman EMA. The fit improved significantly (by $30 \%$ ) when the interfacial layer thickness was set to $30 \AA$, without changing the parameters of the film above it (except to adjust its total thickness). However, because of the complexity of the model and the possibility of hidden parameter correlations, we consider the results for the interface to be only qualitative.

\section{CONCLUSION}

It has been shown that an inhomogeneous $\operatorname{SiO}_{x} \mathrm{~N}_{y}$ thin film structure with nonuniformly graded index profile can be successfully characterized by SE. For the sample studied, both the film thickness and its refractive index profile were determined. The SE data are extremely sensitive to the refractive index profile, as well as the layer thickness. We therefore expect that $\mathrm{SE}$ will prove to be valuable for fast, quantitative, nondestructive, and possibly in situ analysis of more complicated rugate structures.

\section{ACKNOWLEDGMENTS}

The authors acknowledge M. A1-Jassim and A. Franz of SERI for Auger analysis. This work was supported by the U.S. Army under Grant No. DEAL-04-89-C-0021. We also wish to thank Blain Johs at the J. A. Woollam Co. for developing the SE analysis software, which includes the ability to model graded layers.

'W. Southwell, Opt. Lett. 8, 584 (1983).

${ }^{2}$ A. B. Harker and J. F. Denatale, Thin Solid Films 168, 185 (1989).

${ }^{3}$ W. E. Johnson and R. L. Crane, Opt. Interference Coatings Tech. Digest Ser. 8, 118 (1988),

${ }^{4}$ G. A. Al-Jumaily, J. J. MeNally, J. R. McNeil, and W. C. Hermann, Jr., J. Vac. Sci. Technol. A \$, 651 (1985). 
${ }^{5}$ J. J. McNally, K. C. Jungling, F. L. Williams, and J. R. McNeil, J. Vac. Sci. Technol. A 5, 2145 (1987).

${ }^{6}$ P. G. Snyder, M. C. Rost, G. H. Bu-Abbud, J. A. Woollam, and S. A. Aiterovitz, J. Appl. Phys. 60, 3292 (1986).

${ }^{7}$ A. E. T. Kuiper, S. W. Koo, F. H. P. M. Habraken, and Y. Tamminga, J. Vac. Sci. Technol. B 1, 62 (1983).

${ }^{8}$ J. E. Schoenholtz and D. W. Hess, Thin Solid Films 148, 285 (1987).

${ }^{9}$ Y. M. Xiong, P. G. Snyder, J. A. Woollam, G. A. Al-Jumaily, F. J. Gagliardi, and E. R. Krosche, Thin Solid Films 206, 248 (1991).
${ }^{10}$ D. A. G. Bruggeman, Ann. Phys. Leipzig 24, 636 (1935).

${ }^{11}$ R. M. A. Azzam and N. M. Bashara, Ellipsometry and Polarized Light (North-Holland, Amsterdam, 1977).

${ }^{12}$ D. W. Marquardt, J. Soc. Indus. Appl. Math. 11, 431 (1963).

${ }^{13}$ D. E. Aspnes and A. A. Studna, Appl. Opt. 14, 220 (1975).

${ }^{14}$ H. P. Philipp, J. Electrochem. Soc. 120, 295 (1973).

${ }^{15}$ D. E. Aspnes and J. B. Theeten, J. Appl. Phys. 50, 4928 (1979).

${ }^{16}$ E. D. Palik, Handbook of Optical Constants of Solids (Academic, New York, 1985). 